This paper is part of the Proceedings of the $3^{\text {rd }}$ International Conference on Design,

\title{
Current threats to water supply systems
}

\author{
J. Chudzicki \\ Faculty of Building Services, Hydro and Environmental Engineering, \\ Warsaw University of Technology, Poland
}

\begin{abstract}
Water supply systems play an extremely important role in the technical infrastructure of settlement units, ensuring efficient and reliable supply of drinking water to consumers.

There are many different threats to uninterrupted water supply, such as equipment failures, natural disasters or catastrophes. Provision of water supply is especially important nowadays, given the increasing terrorist attack threat to the modern world.

Stoppage of water supply to a large urban area or contamination of drinking water poses a real threat to the health and life of hundreds or even thousands of inhabitants.
\end{abstract}

Paradoxically, in the case of the Polish water supply systems, the aforementioned risks can be realised with relative ease.

The paper identifies the critical points of risk to water supply systems, in particular to point structures and linear structures. It discusses the legal aspects of the control over and the public disclosure of sensitive technical information concerning the hydro-engineering structures.

Keywords: water supply systems, hazards, water supply in crisis conditions.

\section{Introduction}

The occurrence of extreme events results in hardly predictable situations connected with the functioning of individual technical infrastructure elements both on the land surface and underground. The same holds, to a very significant degree, for the equipment used for supplying water to settlement units.

Water supply systems play an extremely important role in the technical infrastructure of settlement units, ensuring efficient and reliable supply of drinking water to consumers $[15,16]$. 
There are many different threats to uninterrupted water supply, such as equipment failures, natural disasters or catastrophes.

Provision of water supply is especially important nowadays, given the increasing terrorist attack threat to the modern world. Stoppage of water supply to a large urban area or contamination of drinking water poses a real threat to the health and life of hundreds or even thousands of inhabitants [3].

Paradoxically, in the case of the Polish water supply systems, the aforementioned risks can be realized with relative ease.

\section{General characteristics of threats to water supply systems}

Uniqueness, randomness, multiple causes, and diversity of direct effects are the characteristic features of events connected with serious accidents and an extraordinary impact of the forces of nature. The events can pose a threat to human health and life, result in environmental degradation or lead to a substantial economic damage [5].

An event caused by a terrorist attack can also be considered a catastrophe or a technical failure. Actions taken by a psychopath or acts of vandalism can bring about similar effects.

Extraordinary situations can be produced both by random natural phenomena, such as torrential rains, hurricanes, melting snow, very low temperatures or hydrological droughts, and accidental failures, catastrophes or even warfare. However, in most cases, water contamination is of an incidental character. Water conditioning plants are designed to cope with typical contamination levels which occur repeatedly, are often of a seasonal nature, and can be characterised numerically and, what is more important, using statistical methods [13]. But occasionally, there may be random and hardly predictable cases of contamination that the water conditioning process is not prepared for. The contamination of that kind may be hazardous. In quantitative terms, there are cases where the capacity of water intakes periodically drops below the level required to satisfy the demand or, due to serious contamination, the water inflow from the intake should be stopped. The incidental contamination can be caused by natural phenomena (e.g. rainfall) or failures/catastrophes (damaged pipelines used e.g. for oil transportation, leaking hazardous chemical storage tanks, uncontrollable industrial wastewater discharges, or road or rail accidents) [4]. Contamination of that kind results in dramatically increasing concentrations of a pollutant, way above the standard levels for a given water source.

\section{Critical elements of a water supply system}

Each water supply system consists of point structures and linear structures. The point structures include such objects as:

- Water sources (water intakes);

- Water conditioning stations;

- Water pumping stations;

- Water supply reservoirs. 
The linear structures in a water supply system are individual elements of a water supply network: transit pipes, water mains and distribution conduits.

From the point of view of possible threats to an uninterrupted operation of a water supply system, each of the aforementioned elements may become a critical one the damage to or failure of which may result in stoppage of the water supply or deteriorated water quality.

In Poland, the point structures are protected quite well. Direct and indirect protection areas are created around water intakes, water conditioning stations, reservoirs or water pumping stations (Fig. 1). The direct protection areas around the point structures are protected additionally by a fence [8].

Since many point structures are operated in an automatic mode, without any staff attending them on a regular basis (except for the water conditioning stations), they are equipped with remote monitoring facilities (CCTV cameras, motion detectors, alarms etc.).

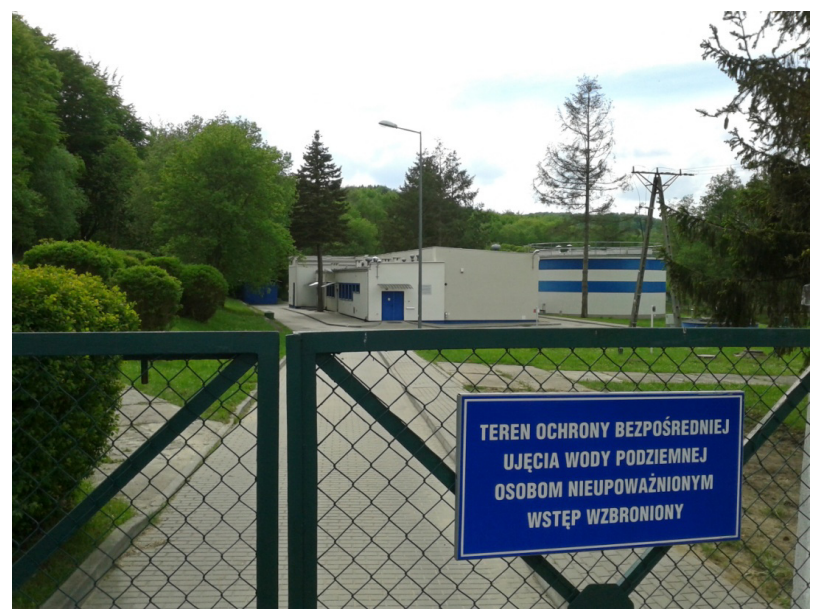

Figure 1: Direct protection area around underground water intake of a local water supply system.

A slightly different approach is applied to the linear structures which are located in a public space, i.e. within the built-up areas of settlement units.

Although the water supply pipes are laid and run underground, in practice there is unconstrained access to them. In Poland, the water supply pipes are laid at the depth of around $1.8 \mathrm{~m}$ below ground level (due to frost penetration and in order to avoid collisions with other elements of the underground infrastructure). Access to the water running in the water supply pipes is theoretically possible through fire hydrants and drinking fountains. The water system connection points are well marked and easy to locate.

The access to the linear elements of a water supply system is particularly easy in dispersed development areas, e.g., in a rural landscape (Fig. 2). 


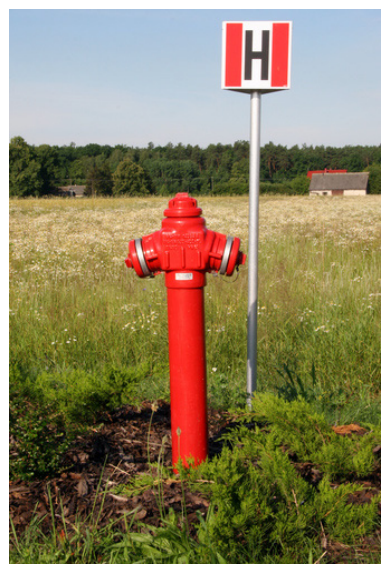

Figure 2: $\quad$ Marked fire hydrant in a water distribution area of a municipal water supply system.

In urban settlement units, within densely developed areas, the risk of unauthorised access to the water supply system is present, too. In this case, various underground infrastructure repair or modernisation work is done more frequently, making it possible to get access to the water supply pipes (Fig. 3). Access to the exterior water supply pipes can be obtained through fire hydrants and water system connection points, as well.

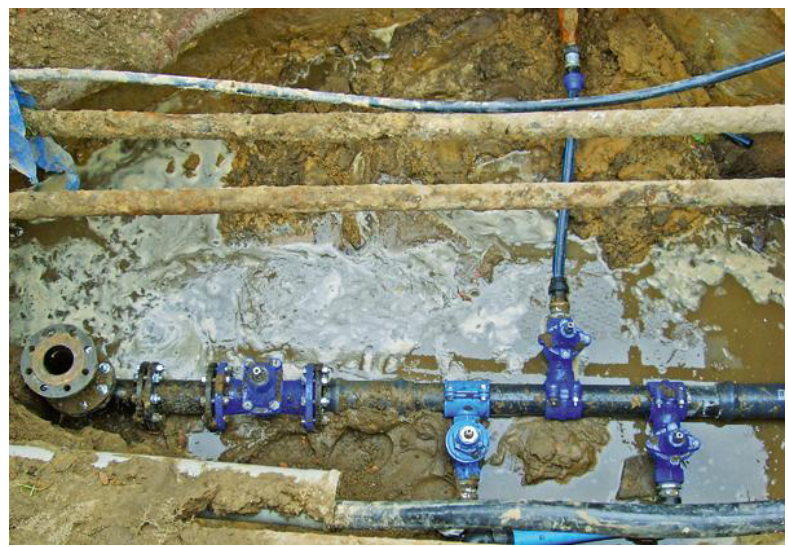

Figure 3: Water supply network in a densely developed area: an example of possible access to pipes running underground. 


\section{Possible types of threats to critical elements of a water supply system}

The following types of possible threats to a water supply system can be identified in the case of a water supply system divided into point and linear structures:

- Damage to critical points of the system;

- Secondary contamination and pollution of water in the distribution network;

- Surface flooding (due to damaged wastewater systems);

- Contamination of surface and ground water (source of water for water intakes);

- Availability of information about the water supply system in a public space.

Failures of the water supply system are the main threat to an uninterrupted water supply [11]. They can be of a random and accidental nature or result from actions taken by terrorist groups or sheer vandalism. A water supply system failure always entails the risk of a secondary contamination and pollution of the water in the distribution system (Fig. 4) [1, 4].

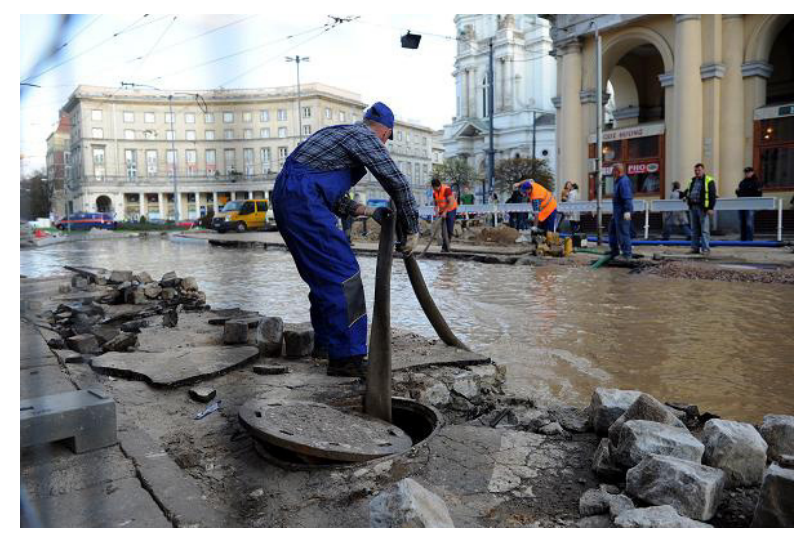

Figure 4: Water supply pipe failure in Warsaw, Poland.

In situations of that kind there is a need to provide additional water supply for the inhabitants of the area affected by the water network failure.

A similar threat to an uninterrupted water supply from the distribution network occurs in the case of flooding or permeation of an area and a consequent hazard of pollutants (present on the ground surface) penetrating the catchment area of the water intakes used by a local water supply system (Figs 5 and 6).

As far as the linear elements of the system are concerned it is theoretically possible to get an unauthorised access to a water distribution system quickly and easily. It is possible to connect to a water supply system in no time even if the 
system is in operation. Usually the connection is made by means of a spotter, pipe fittings and tools which are generally available (Fig. 6).

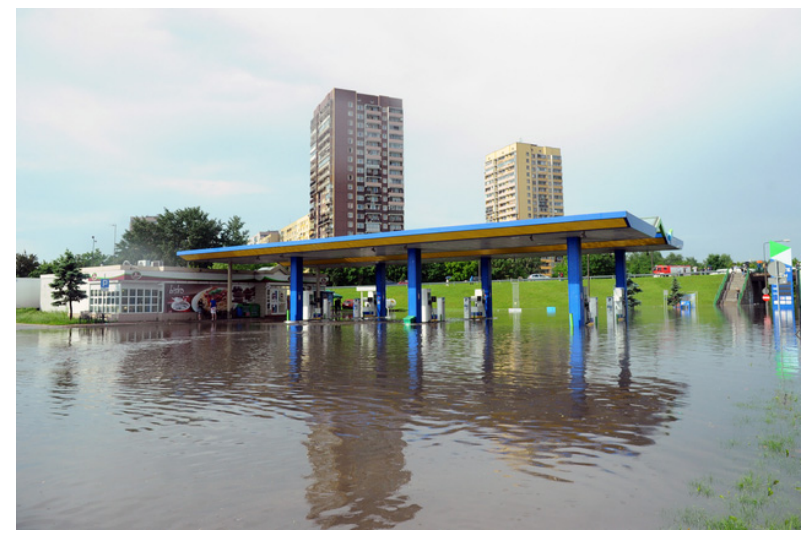

Figure 5: Petrol station flooded by torrential rain (Warsaw, June 2013).

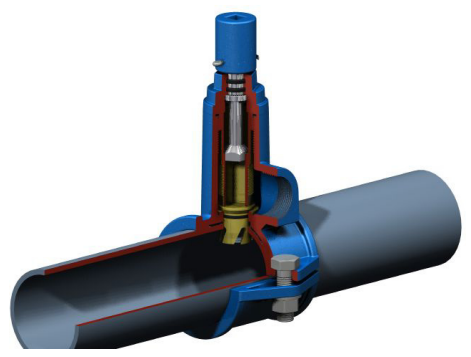

(a)

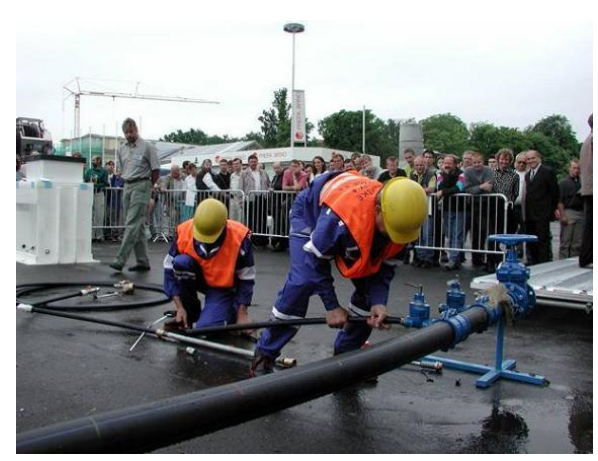

(b)

Figure 6: Connection to a water supply pipe by means of a spotter: (a) diagram showing a spotter installed on a pipe and (b) quickest connection contest held during the Trade Fair of Installations (the winning team time: around $4 \mathrm{~min}$.).

The threat of tampering with an operational water distribution system consists first and foremost in the possible secondary contamination and pollution of the transported water [1]. One conceivable option is an illegal connection to an existing water supply pipe but you can use a fire hydrant for that purpose, as well. By means of a small pump kit it is possible to force any substance into the water supply system to contaminate the water and the entire distribution network (Fig. 7). 


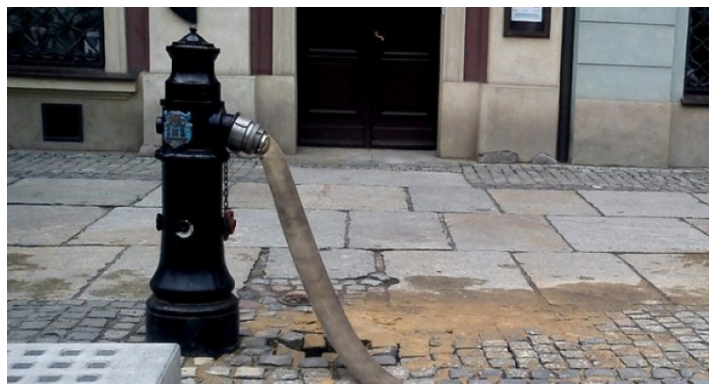

Figure 7: Possible access to a water supply network through a fire hydrant.

The aforementioned types of risks to a water supply system are relatively easy to realize in reality. It is so because the technical information about a water supply network is generally available on the Internet.

The Public Procurement Law Act imposes an obligation on municipal and poviat authorities to make detailed technical documentation on the construction and extension of water supply networks available to the general public [7]. The water supply companies more and more frequently use GIS database systems [6], containing highly sensitive data about individual elements of a water supply network.

There are geodesic data showing individual underground utility components (technical infrastructure), including the information about water supply network elements, available on geodesic websites and in cadastral databases on the internet (Figs 8 and 9).

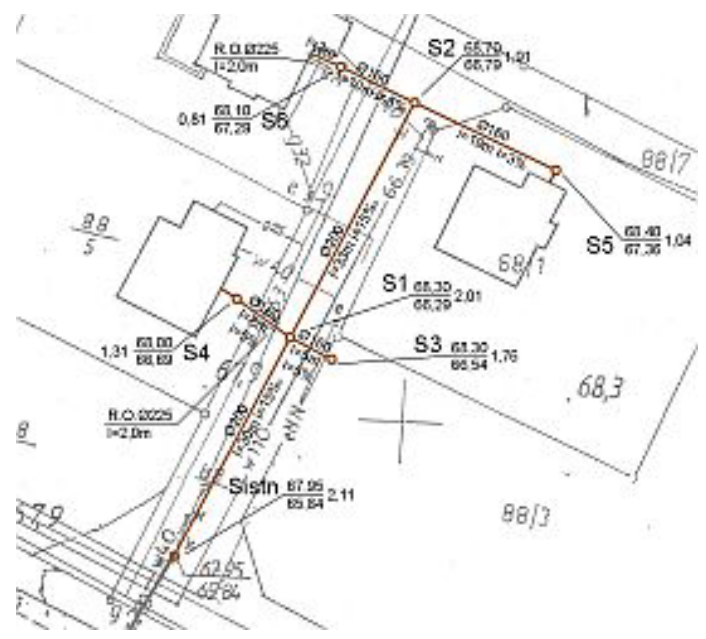

Figure 8: Fragment of a project documentation drawing published on the internet. 


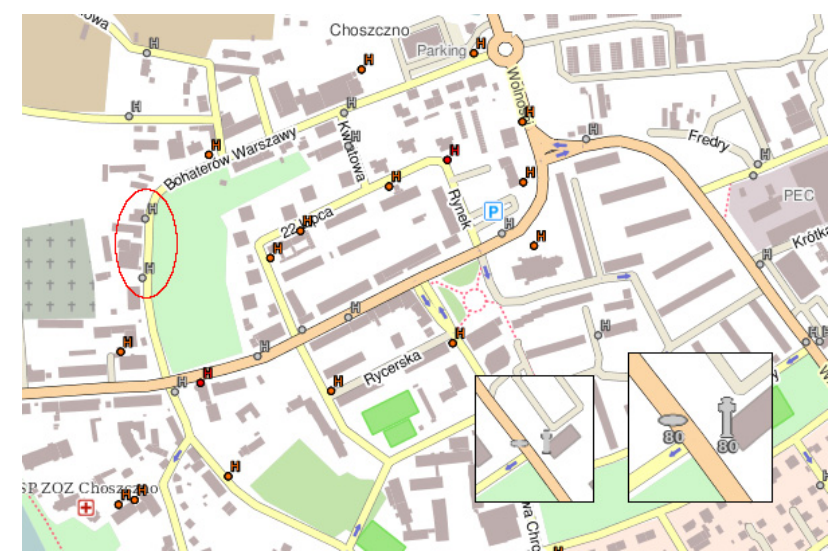

Figure 9: Fragment of GIS database visualisation with indicated fire hydrant locations.

An additional usage opportunity is provided by generally accessible computer tools, e.g. those designed to be used for hydraulic modelling of water supply systems or spread of contamination in the systems (EPANET). If you have just some engineering knowledge about the functioning of a water distribution network by means of those tools you can easily determine the weakest spot in the network which can be used for water contamination purposes.

The sensitive character of access to data about the underground infrastructure has already attracted some attention in the countries of the European Union [12]. Since 2008, efforts have been made to monitor the level of protection of the data in individual member states.

As the example of Poland shows, the risk of an unauthorised access to data about water supply systems continues to be relatively high.

\section{Threat countermeasures}

\subsection{General principles}

The main structural effort aimed at improving the operational reliability of a water supply system consists of designing the system in a way that various water production and distribution routes are available. In practice, redundancy is used for that purpose: designs provide for multiple equipment units and point structures, e.g. redundant process lines in water conditioning stations or several pumps in pumping stations, or a ring layout of a system used for transmission and supply of water to consumers.

In the ongoing operation and maintenance process the water sent through water supply networks is protected against secondary contamination by means of anti-contamination equipment $[1,2]$. However, such an approach does not guarantee an effective protection of water supplies in every crisis situation [10]. 
For the purposes of considering various solutions to the problem of water supply to a city in special circumstances alternative scenarios of relevant actions are developed. It is important to take into account the time it takes to restore the system which supplies water to a settlement unit back to its normal operational status. The paper [3] suggests that the criterion of time should be used as the basis for taking adequate measures to restore water supply and this criterion comes in three variants:

Variant I: Repair of the system and restoration of water supply to a city within up to 48 hours.

Variant II: Repair of the system and restoration of water supply to a city within the period of 2 days to 4 weeks.

Variant III: Repair of the system and restoration of water supply to a city within the period of one month to one year.

\subsection{Variant 1: water supply failure for up to 48 hours}

Variant I is employed in the situation existing for the first dozen or so hours following the occurrence of the crisis event. It is assumed that the period of the first two days and nights since the emergence of such a situation is required for the affected water supply system to recover and get back to its fully operational status. Since the assumed water supply system recovery time is relatively short, a minimum unit quantity of water to be supplied to an urban area per person has been determined, in this case the minimum is 7.5 cubic $\mathrm{dm} / 24$ hours. This is the smallest possible daily amount of water per person, as defined in the regulation [8] in Poland.

In this variant the water is supplied to the inhabitants by means of tank trucks (non-potable water for domestic use) and distribution of packaged water (drinking water).

\subsection{Variant 2: water supply failure for 2 days to 4 weeks}

Variant II is employed in the situation where the estimated time needed for an urban water supply system to get back to its fully operational status is from 2 days to 4 weeks. Since the assumed water supply system recovery time is longer than that specified in variant $\mathrm{I}$, the minimum amount of water to be supplied to the urban area inhabitants is 15 cubic $\mathrm{dm} / 24$ hours, as defined in the regulation [8].

In this variant it seems reasonable to use temporary water storage tanks, e.g. in the form of pillow-shaped flexible vessels made of PVC or PE (Fig. 10). 


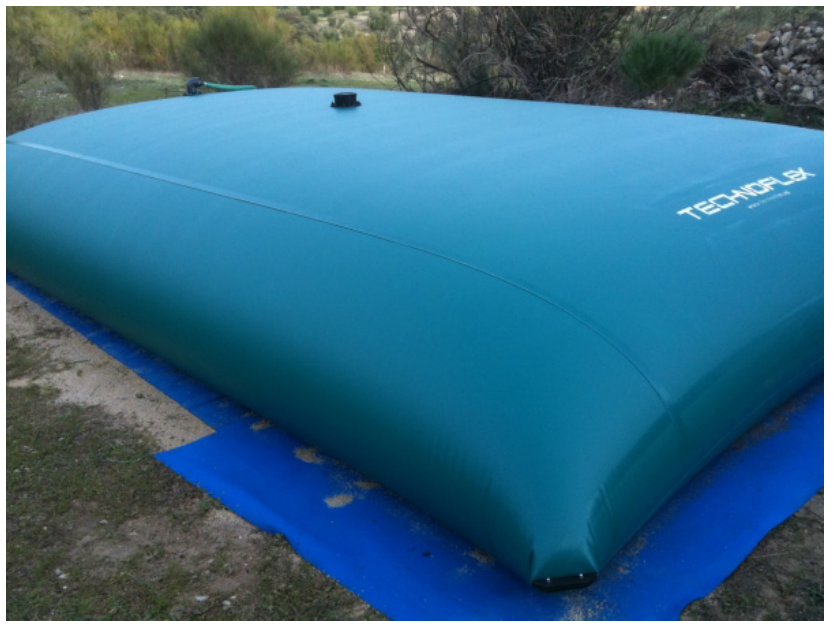

Figure 10: Water tank made of PVC (Technoflex).

\subsection{Variant 3: water supply failure for 1 month to 1 year}

Variant III is of the most catastrophic character because the estimated time needed for the restoration of the full operational capacity of an urban water supply system may be as long as several months or even up to one year. Since the period of time assumed in variant III is much longer than that specified in the previous two variants, it is recommended to increase the minimum amount of water supplied per person up to 30 cubic $\mathrm{dm} / 24$ hours.

This amount is sufficient for essential hygienic operations, drinking, preparation of meals, bathing, dish washing and manual laundry but does not include car washing or lawn watering [9].

In the case of an extreme situation where the restoration of a normal operational status of a water supply network may take from several months to one year, the following actions should be taken:

- Distribution of bottled of packaged water among the inhabitants;

- Delivery of water by tank trucks;

- Distribution of water by tank trucks to water reservoirs located in residential neighbourhoods;

- Use of some fragments of water supply networks as underground reservoirs;

- Drilling new wells to create alternative water intakes.

In the case of a long-term water supply failure it is recommended to take into consideration the use of some fragments of the water supply systems as underground water reservoirs.

On a parallel basis, it is necessary to launch the process of obtaining water from alternative sources, first and foremost using the ground water intakes since they are less exposed to the contamination risk. Crisis management plans developed for urban and rural settlement units in Poland take into account planned locations for new wells. 


\section{Conclusion}

The paper discusses the current situation connected with a potential threat of access to sensitive data about water supply systems. The situation may represent a certain risk especially nowadays, given the increased threat of terrorist attacks. Practical examples from Poland were used for demonstrating the easiness of access to detailed technical information about existing and planned water supply system structures. Possible unauthorised access to the linear structures (transportation pipelines, water distribution networks) is of particular importance because they are located in a public space and, consequently, are less protected and more exposed to illegal manipulation or tampering. The situation of the point structures is better because they are easier to protect and guard.

The final part of the paper specifies actions which should be taken in the case of a water supply system failure depending on the time it takes to restore normal water supplies. In accordance with basic requirements of the law the European Union member states apply regulations in a way to make the possible actions taken in a public space (e.g. water supply) transparent at each stage of a project implementation. However, this strength of a state may become its weakness in the case of a direct threat or attack. Unfortunately, the possibilities of that kind must be taken into account in the present situation.

\section{References}

[1] Chudzicki J., Kwietniewski M., Iwanek M., Suchorab P. Secondary contamination in Polish drinking water. Urban Water II, Edit. Mambretti S., Brebbia C.A. WITPress, UK, 2014, ISBN 978-1-84564-780-3, pp. 1526.

[2] Chudzicki J., Sosnowski S. Instalacje Wodociągowe - projektowanie, wykonanie,eksploatacja. Published by Seidel-Przywecki, Warsaw 2011. ISBN 978-83-60956-25-0.

[3] Collective work (Edit. Najgebauer A.) Modele zagrożeń aglomeracji miejskiej wraz z systemem zarządzania kryzysowego na przykładzie miasta stołecznego Warszawy. Published by WAT, Warsaw 2009. ISBN 978-83-61486-22-0.

[4] Iwanek, M., Kowalska, B., Hawryluk, E., Kondraciuk, K. Distance and time of water effluence on soil surface after failure of buried water pipe. Laboratory investigations and statistical analysis. Maintenance and Reliability, 18 (2), pp. 278-284, http://dx.doi.org/10.17531/ein.2016.2.16, 2016.

[5] Iwanek, M., Kowalski, D., Kwietniewski, M. Model Studies of a Water Outflow from an Underground Pipeline Upon Its Failure. Ochrona Srodowiska, Vol. 37, No. 4, pp. 13-17, 2015.

[6] Kwietniewski M. GIS in Water Supply and Wastewater Systems. PAN, Warsaw 2008, ISBN 978-83-89687-34-0.

[7] Public Procurement Law Act (Official Journal of 2015, Item 2164). 
[8] Regulation No 2/95 on Principles of Ensuring the Operation of Public Water Supply Facilities under Special Circumstances issued by Minister of Spatial Development and Construction on 21 September 1995 (SO807/95).

[9] Regulation on Determination of Standard Average Water Consumption Levels issued by Minister of Infrastructure on 14 January 2002 (Official Journal No 8/2002, Item 70).

[10] State of Natural Disaster Act of 18 April 2002 (Official Journal No 62, Item 558).

[11] Tchórzewska-Cieślak B., Pietrucha-Urbanik K.: Failure risk analysis in the collective water supply systems in crisis situations. vol. 4, pp. 129-136, 2013 Polish Safety and Reliability Association, Journal of Polish Safety and Reliability Association, Summer Safety and Reliability Seminars, vol. 1.

[12] UPSIDEDOWN PROTECT - European Project: Spatial Data Protection for the Underground Critical Infrastructures. Programme: Prevention, Preparedness and Consequence Management of Terrorism and Other Security Related Risks. Agreement HOME/2011/CIPS/AG40000021108 ABAC. (www.upsidedownprotect.eu).

[13] Zimoch, I. Analysis of Operational Safety as a Tool for Controlling the Functioning of a Water Treatment Plant. Ochrona Srodowiska, Vol. 33, Issue 2, pp. 39-44, 2011.

[14] Zimoch, I. Assessing spatial variations of water quality in the water-pipe network by analysis of THM formation. Ochrona Srodowiska, Vol. 29, Issue 4, pp. 49-52, 2007.

[15] Zimoch, I. Pressure Control as Part of Risk Management for a Water-pipe Network in Service. Ochrona Srodowiska, Vol. 34, Issue 4, pp. 57-62, 2012.

[16] Zimoch, I; Lobos, E. Comprehensive interpretation of safety od wide water supply systems. Environment Protection Engineering, Vol. 38 (3), pp. 107-117, 2012. 